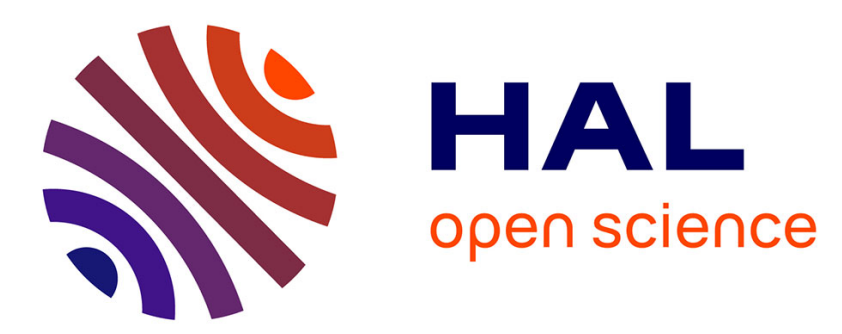

\title{
Cross-conjugated BODIPY pigment for highly efficient dye sensitized solar cells
}

Md Faiz Shah, Antoine Mirloup, Towhid Chowdhury, Ryuji Kaneko, Alexandra Sutter, Abdulkader Hanbazazah, Anas Ahmed, Jae-Joon Lee, M. Abdel-Shakour, Nicolas Leclerc, et al.

\section{To cite this version:}

Md Faiz Shah, Antoine Mirloup, Towhid Chowdhury, Ryuji Kaneko, Alexandra Sutter, et al.. Crossconjugated BODIPY pigment for highly efficient dye sensitized solar cells. Sustainable Energy \& Fuels, 2020, 4 (4), pp.1908-1914. 10.1039/C9SE01090D . hal-03000122

\section{HAL Id: hal-03000122 \\ https://hal.science/hal-03000122}

Submitted on 29 Nov 2020

HAL is a multi-disciplinary open access archive for the deposit and dissemination of scientific research documents, whether they are published or not. The documents may come from teaching and research institutions in France or abroad, or from public or private research centers.
L'archive ouverte pluridisciplinaire HAL, est destinée au dépôt et à la diffusion de documents scientifiques de niveau recherche, publiés ou non, émanant des établissements d'enseignement et de recherche français ou étrangers, des laboratoires publics ou privés. 


\section{Cross-Conjugated BODIPY Pigment for Highly Efficient Dye Sensitized Solar}

2 Cells

3

4 Md Faiz Shah, ${ }^{\text {a }}$ Antoine Mirloup, ${ }^{\text {}}{ }^{*}$ Towhid H. Chowdhury, ${ }^{\text {c.d }}$ Ryuji Kaneko, ${ }^{c}$ Alexandra 5 Sutter, ${ }^{\text {b }}$ Abdulkader S. Hanbazazah, ${ }^{\text {a }}$ Anas Ahmed, ${ }^{\mathrm{a}}$ Jae-Joon Lee, ${ }^{\mathrm{d}}$ M. Abdel-Shakour, ${ }^{\mathrm{c}}$ Nicolas

6 Leclerc, $^{\mathrm{b} *}$ Ashraful Islam. ${ }^{\mathrm{c} *}$

$8{ }^{a}$ Department of Industrial Engineering, University of Jeddah, Kingdom of Saudi Arabia

9 b Institut de Chimie et Procédés pour l'Energie, l'Environnement et la Santé (ICPEES), Université

10 de Strasbourg, CNRS, UMR 7515, 25 rue Becquerel, 67087 Strasbourg, Cedex 02, France

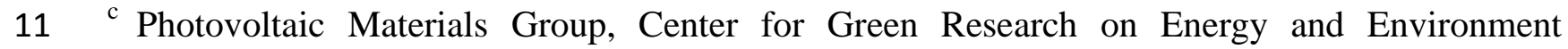

12 Materials, National Institute for Materials Science, Sengen 1-2-1, Tsukuba, Ibaraki 305-0047,

13 Japan.

$14{ }^{\mathrm{d}}$ Department of Energy \& Materials Engineering \& Research Center for Photoenergy Harvesting 15 and Conversion Technology (phct), Dongguk University, Seoul 04620, Republic of Korea.

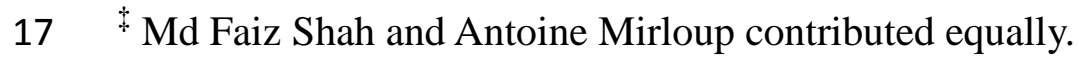

Corresponding author: Islam.Ashraful@nims.go.jp; leclercn@unistra.fr

Keywords: Dye sensitized solar cells; Cross conjugation; BODIPY Dyes; Panchromatic sensitizer; Co-sensitization; NIR absorption

\section{Abstract}

In this study, we report a new BODIPY-based design, called cross-conjugated design, that takes advantage of the $\alpha$ - and $\beta$-positions functionalization of the BODIPY core. After synthesis, and compared to a more standard BODIPY dye, using similar functional groups and based on a

28 horizontal design, called $\boldsymbol{h}$-BOD, the new cross-conjugated BODIPY dye (cc-BOD) exhibits clearly the highest conjugation and light harvesting properties. Consequently, when used as photosensitizers in dye-sensitized solar cells (DSSCs), an impressive improvement of power conversion efficiency (PCE) has been observed, with a PCE of 6.02\% with broad incident photon 
32 to current conversion efficiency (IPCE) for $\boldsymbol{c c}$-BOD, compared to only $3.7 \%$ for $\boldsymbol{h}$-BOD.

33 Moreover, by co-sensitizing a DSSC with the two complementary absorbing dyes $\boldsymbol{h}$-BOD and

$34 c c$-BOD, we further improved the PCE up to $6.2 \%$.

35

\section{Introduction}

Since its first inception in 1992 by Gratzel ${ }^{1}$, dye sensitized solar cells (DSSCs) have been a popular choice of solar energy source due to their versatile impacts, such as easy fabrication process, light weight and flexible physical structure. Generally, DSSCs are fabricated with an electrode, a dye sensitizer, electrolytes, a counter electrode sandwiched between two transparent conducting substrates ${ }^{2,3}$. Among all the other components, the dye contributes to determine the photovoltaic response of the overall device by harvesting efficiently and by injecting the photogenerated electrons and holes into, respectively, the semiconductor oxide and the redox electrolyte, with matched energy levels ${ }^{4,5}$. In this regard, a vast amount of dyes have been implemented in DSSCs, which can be categorized into metal-based dyes and organic dyes. In terms of photovoltaic responses, metal-based dyes show superior performances but due to low yield and scarcity of source materials they remain quite unattractive ${ }^{6,7}$. Metal free organic dyes with easy synthesis processes have shown promising or even equal photovoltaic performances in DSSCs ${ }^{8-11}$. The advantages of organic dyes over metal-based dyes rely on their ability to absorb light in specific wavelengths with high molar extinction coefficient ${ }^{12-14}$. The molecular engineering and tailoring of different light absorbing functional groups can lead to a light harvesting tuning over a broad spectral range resulting in highly efficient DSSCs ${ }^{15-21}$. Borondipyrromethene (BODIPY) dyes are among the most widely considered chromophores thanks to their unique optical properties, including high absorption coefficients in the visible and NIR ranges and high fluorescence quantum yields ${ }^{22}$. In addition, BODIPY dyes often exhibit a high stability in various media. Last but not least, the high number of reactive chemical positions allow a very fine tuning of their opto-electronical properties. Therefore, BODIPY-based molecules have found application in a numerous field of application such as Organic Light Emitting Diodes (OLED) ${ }^{23}$ (bio)-labeling ${ }^{24}$ photodynamic therapy ${ }^{25}$, or photovoltaic devices, including organic ${ }^{26}$ and hybrid technologies ${ }^{27}$.

The numerous chemical modifications of the BODIPY core, have made it possible to highlight 
62 the weak points of this chemical building block that need to be improved to increase the dye 63 performances in DSSC devices and consequently the power conversion efficiencies (PCE) ${ }^{28-31}$.

64 These issues are the following: i) A weak regeneration driving force between the ground state 65 oxidation potential (highest occupied molecular orbital, HOMO) of the dye and the redox 66 potential of the iodine/iodide redox electrolyte ${ }^{32}$. ii) A weak driving force for the injection of the

67 excited state electron into the $\mathrm{TiO}_{2}$ resulting from the usual inappropriate alignment of the 68 BODIPY dyes lowest unoccupied molecular orbital (LUMO) energy level is too near to the 69 conduction band (CB) of $\mathrm{TiO}_{2}$ photoanode. Consequently, the BODIPY based DSSCs often show 70 low incident photon-to-current conversion efficiency (IPCE) ${ }^{33,34}$. iii) A strong aggregation of the 71 flat BODIPY sensitizers on the surface of $\mathrm{TiO}_{2}$ leading to low charge recombination, which 72 decreases the device open-circuit photovoltage.

73 Chemical engineering has already brought some positive answers to these issues, such as the 74 variation of the number of functionalized groups grafted onto the 3,5-positions of the BODIPY 75 core, allowing to tune the final dye LUMO level ${ }^{35}$. Similarly, the aggregation related issue could 76 be addressed by playing with the steric hindrance of side chains. For instance, the boron 77 substitution by inert alkynyl-oligoethylene glycol chains has shown to be a good strategy to 78 increase both solubility and stability and to suppress the dye aggregation. ${ }^{36,37}$ However, despite 79 the positive evolution of chemical designs and device efficiencies, the rationalization of the 80 chemical structure - photovoltaic properties relationship is still difficult. Therefore, new dye 81 investigations are required. In a recent review related to the use of BODIPY dyes for the DSSC 82 application, Klfout et al. ${ }^{28}$ defined two distinct dye design strategies (see Figure 1) i.e. the 83 vertical design in which the functional electron-donor (D) and electron-acceptor (A) groups are 84 grafted vertically to the BODIPY core main plane, by using the 3- and 5-positions (usually for D) 85 on one side and the 8 (meso)-position for the A group grafting; and the horizontal design in 86 which the D and A groups are grafted horizontally, on each side of the BODIPY core, by using 87 the 2- and 6-positions of the BODIPY molecule.

89 In this study, we report an innovative design, called cross-conjugated design, by combining the 90 horizontal and vertical design in one single dye (see Figure 1). Indeed, we used three different (2, 913 and 5) positions to substitute the electron donor groups and the position 6 to graft the electron92 acceptor/anchoring group (see Figure 1, $\boldsymbol{c c}$-BOD). In order to validate this chemical design, we 
93 also synthesized a reference model, based on the only horizontal design by removing the donor 94 groups in the 3- and 5-positions (see Figure 1, $h$-BOD). The synthesis, spectroscopic 95 characterization, electrochemistry, and photovoltaic properties of these compounds have been 96 evaluated in detail. The cross-conjugated BODIPY dye, $\boldsymbol{c c}$-BOD, exhibits a very broad 97 absorption spectrum up to $760 \mathrm{~nm}$, when adsorbed on $\mathrm{TiO}_{2}$ photoanode and leads to a high PCE 98 value of $6.02 \%$ when used as sensitizer in a DSSC. Interestingly, the simpler $\boldsymbol{h}$-BOD dye showed 99 a narrower and blue-shifted absorption range, limited to $650 \mathrm{~nm}$ leading to a lower PCE value of 100 only $3.7 \%$. The differences in the photovoltaic responses validate our new cross-conjugated 101 design. Finally, by utilizing the complementary absorption spectra of both dyes, co-sensitized 102 DSSCs were successfully fabricated to a slightly increased PCE of $6.20 \%$.
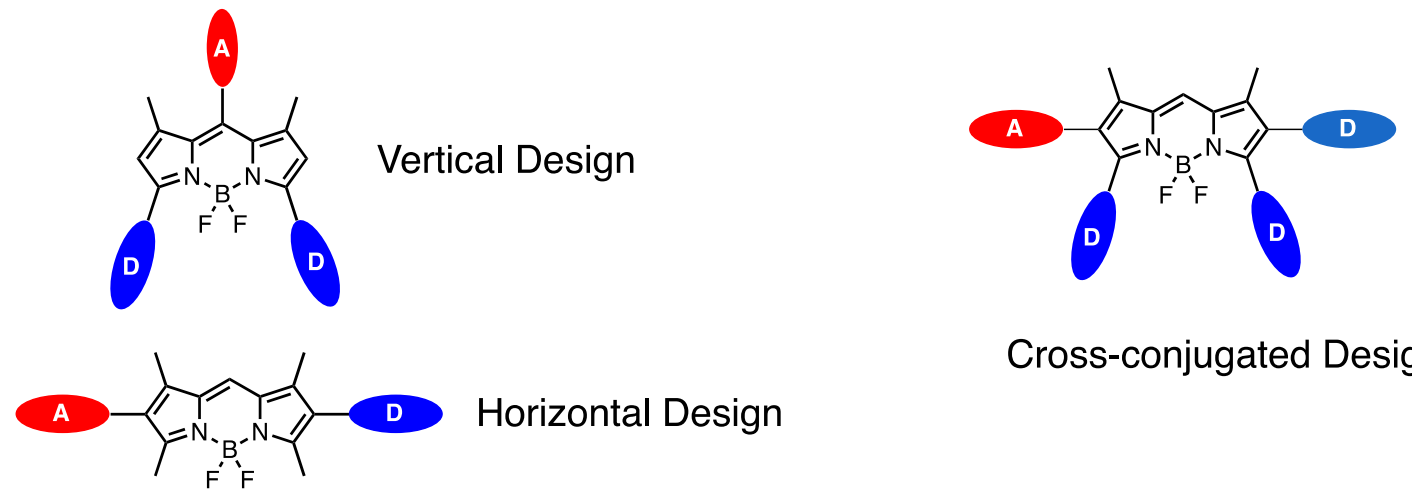

Cross-conjugated Design
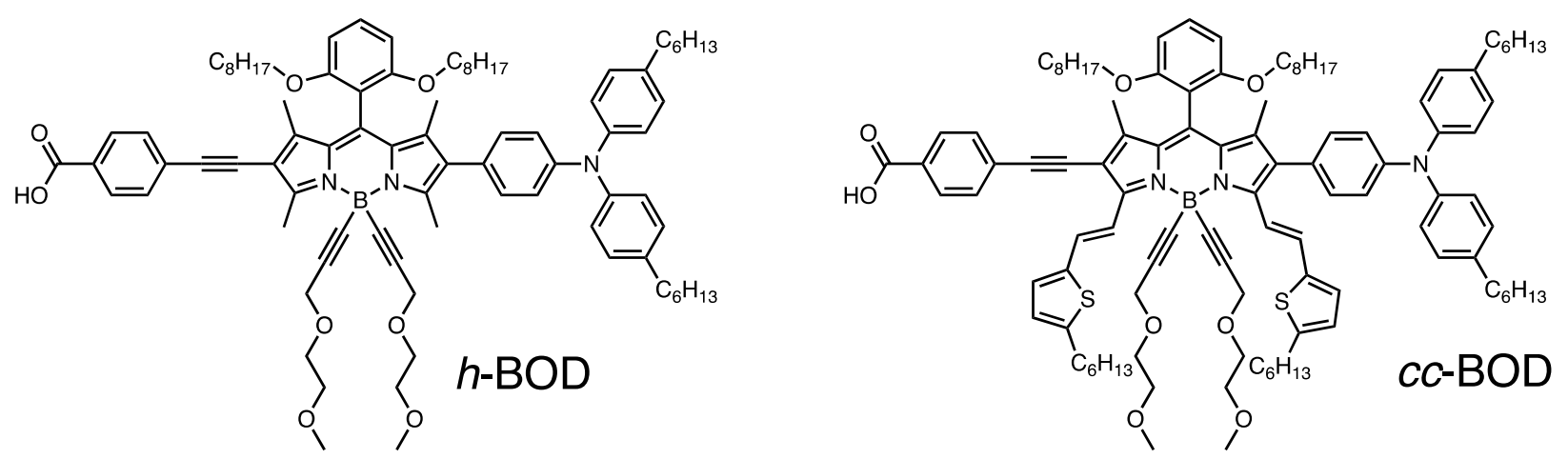

Figure 1. Top. Chemical design strategies; Bottom. Molecular structures of $h$-BOD and $c c$-BOD

\section{Experimental Section}

The starting compounds in Scheme 1 were prepared according to the reported works ${ }^{32-34}$ and 111 Fluorine-doped tin oxide (FTO) coated glass and the DSSCs were fabricated following the 
112 methodology of our previous work ${ }^{36}$. Briefly, prior to dye adsorption the $\mathrm{TiO}_{2}$ film was further 113 treated with $0.1 \mathrm{M}$ solution of $\mathrm{HCl}$. A solution of BODIPY dyes $\left(2 \times 10^{-4} \mathrm{M}\right)$ and deoxycholic 114 acid $\left(1 \times 10^{-2} \mathrm{M}\right)$ in acetonitrile/tert-butyl alcohol $(1 / 1, \mathrm{v} / \mathrm{v})$ was used as a dye bath for a single

$115 h$-BOD or $c c$-BOD based DSSCs. For the co-sensitized DSSCs, the $\mathrm{TiO}_{2}$ photoanodes were 116 immersed into a mix dye solution of $h$-BOD and $c c$-BOD with molar ratio of $1: 2\left(1.3 \times 10^{-4} \mathrm{M}\right.$ : $\left.1172.6 \times 10^{-4} \mathrm{M}\right)$ containing $1 \times 10^{-2} \mathrm{M}$ deoxycholic acid in 1:1 acetonitrile and tert-butyl alcohol. 118 The electrodes were immersed in the dye solutions and then kept at $35{ }^{\circ} \mathrm{C}$ for $12 \mathrm{~h}$ to adsorb the 119 dye onto the $\mathrm{TiO}_{2}$ surface. Each BODIPY-coated $\mathrm{TiO}_{2}$ film and a Pt-coated conducting glass 120 were separated by a $40 \mu \mathrm{m}$ thick polymer-based spacer (Surlyn) and sealed by heating the Surlyn 121 frame at $100{ }^{\circ} \mathrm{C}$. An electrolyte consisting of a mixture of $\mathrm{I}_{2}(0.05 \mathrm{M})$, LiI, (0.1 M), 122 dimethylpropyl-imidazolium iodide $(0.6 \mathrm{M})$, and tert-butylpyridine $(0.05 \mathrm{M})$ in acetonitrile was 123 used. BODIPY dye coated $\mathrm{TiO}_{2}$ films were immersed in $0.1 \mathrm{M}$ TBAOH solution (1:1 mixture of $124 \mathrm{H}_{2} \mathrm{O}$ and ethanol) to desorb the dyes. The absorption peak of each resulting BODIPY single and 125 co-sensitized dye solution was used to estimate the amount of adsorbed dye. The details method for the characterization of solar cells has been provided in supporting information S1-S2 .

\section{Results and discussion}

\subsection{Synthesis of BODIPY dyes $h$-BOD and $c c$-BOD}

131 The cross-conjugated design involved in this work, is partially inspired by the work of Grätzel 132 et al. on the YD2-o-C8 porphyrin derivative ${ }^{38}$. Indeed, based on our knowledge regarding the 133 functionalization of BODIPY molecules for light harvesting applications, we have grafted vinyl134 thiophen groups on the 3- and 5-positions ${ }^{39}$, in order to obtain a wide electronic delocalization. 135 The original idea of this work is to take advantage of BODIPY's chemical versatility to add a 136 lateral push-pull effect by functionalizing in 2- and 6- positions. The synthesis of compounds $\mathbf{1}$, $137 \mathbf{A}$ and $\mathbf{B}$ could be found in the supplementary information as well as details regarding the 138 chemical analysis of all compounds. The 3,5-difunctionalized BODIPY 2 has been obtained by a 139 Knoevenagel reaction between the BODIPY 1, never reported in literature, and the aldehyde A 140 (usually in excess) in the presence of piperidine and trace amounts of $p$-TsOH. The color of the 141 reaction mixture was used to follow the reaction steps (magenta for mono-substitution and blue 142 for the expected di-substitution). From this stage, the two $\boldsymbol{h}$-BOD and $\boldsymbol{c c}$-BOD dyes are 143 synthesized in the same way, following exactly the identical synthesis steps. Thus, the second 
144 step made use of a Grignard reagent capable of transforming the $\mathrm{BF}_{2}$ fragment into $145 \mathrm{~B}$ (alkynylPEG) $)_{2}$ (Scheme 1). The substitution of the first iodo group with the triphenylamine 146 derivative, $\mathbf{B}$, was achieved through Suzuki coupling in presence of $\mathrm{K}_{2} \mathrm{CO}_{3}$ and $\left[\mathrm{Pd}\left(\mathrm{PPh}_{3}\right)_{2} \mathrm{Cl}_{2}\right]$ 147 (compounds 5 and 6). While, the second Iodo group was substituted with phenylcarboxyester 148 using $\mathrm{NEt}_{3}$ and copper iodide in presence of $\left[\mathrm{Pd}\left(\mathrm{PPh}_{3}\right)_{2} \mathrm{Cl}_{2}\right]$ catalyst to give compounds 7 and $\mathbf{8}$, 149 respectively. Finally, the resulting esters were hydrolyzed to the acids, leading to the target dyes $150 \boldsymbol{h}$-BOD and $\boldsymbol{c c}$-BOD, respectively. All the synthesized compounds were characterized using 151 NMR (see supplementary information).

152

153

154

155

156

157

158

159

160

161

162

163

164

165

166

167
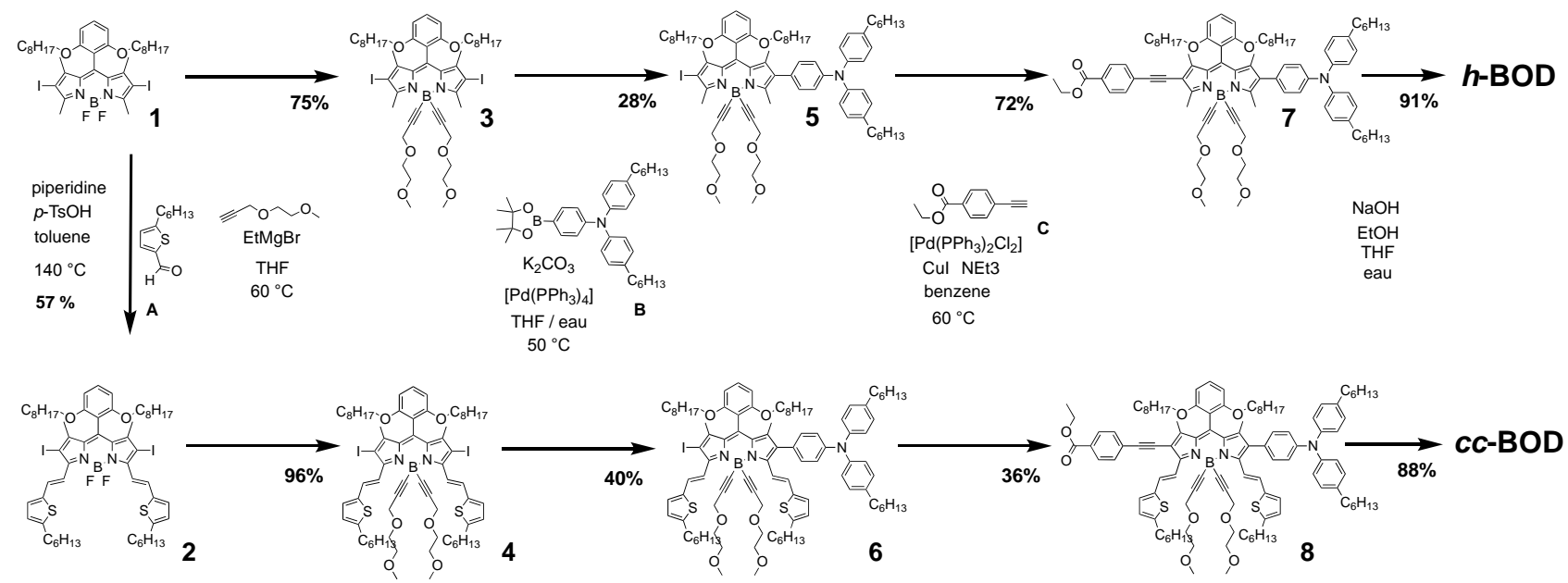

Scheme 1. Synthetic routes for the Bodipy dyes, $\boldsymbol{h}$-BOD and $\boldsymbol{c c}$-BOD.

\subsection{Optical and electrochemical properties}

The optical characteristics, of both new BODIPY dyes were inspected and are summarized in Table 1. Absorption and emission spectra in THF solution of both dyes are illustrated in Figure 2. The model compound, $\boldsymbol{h}$-BOD, exhibits a quite narrow two bands absorption spectrum. The lower energy band, centered on $553 \mathrm{~nm}$, has strangely no vibronic signature, as usually observed in BODIPY-based dyes. The related molar extinction coefficient value is of $54000 \mathrm{M}^{-1} \cdot \mathrm{cm}^{-1}$. The band at higher energy could be attributed to the triphenylamine group absorption. The $\boldsymbol{h}$-BOD emission spectrum (See figure S6) shows a broad feature and a large stokes shift of $2600 \mathrm{~cm}^{-1}$ as regards to the absorption. This is a signature of a strong molecular polarization in the excited state, as already shown in literature for many $\beta$-functionalized BODIPY dye ${ }^{40}$. The $c \boldsymbol{c}$-BOD spectroscopic features are quite different. Its absorption spectrum has three absorption maxima 
168 and is significantly red-shifted compared to the model compound. The one with the lowest 169 energy is at $688 \mathrm{~nm}$ and can be attributed to the $S_{0} \rightarrow S_{1}$ transition ${ }^{41}$. This time, a clear vibronic 170 structure can be observed, with a first shoulder at $628 \mathrm{~nm}$ and a second one, lower in intensity, at 171 about $580 \mathrm{~nm}$. The molar extinction coefficient associated with this transition is of $103000 \mathrm{M}^{-}$ $172{ }^{1} . \mathrm{cm}^{-1}$. The second transition is around $400 \mathrm{~nm}$ and seems to be split. As described previously in 173 the literature ${ }^{39}$, this transition can be attributed to the absorption of vinyl-thiophene arms. 174 However, because of the unsymmetrical functionalization of $c c$-BOD in the 2,6-positions, these 175 two moieties are no longer equivalent in this case and consequently, the absorption is split into 176 two bands. The last transition at $310 \mathrm{~nm}$ corresponds to the absorption of the triphenylamine 177 group. The absorption properties characterization highlights very well the strong and positive 178 impact of our new cross-conjugated design strategy with a dye that exhibits a broader and intense 179 absorption all along the UV-visible range. The $c c$-BOD molecule emits light with a maximum 180 located at $708 \mathrm{~nm}$ and a good quantum fluorescence efficiency of 33\% (See figure S7). With the 181 shoulder at lower energy, this band is characteristic of the BODIPY $\mathrm{S}_{1} \rightarrow \mathrm{S}_{0}$ transition. This 182 spectrum is the mirror image of the absorption spectrum and Stokes shift of around $410 \mathrm{~cm}^{-1}$ 183 could be measured. From UV-visible solution measurements optical bandgaps have been 184 measured, $2.06 \mathrm{eV}$ and $1.71 \mathrm{eV}$, for $\boldsymbol{h}$-BOD and $\boldsymbol{c c}$-BOD, respectively.

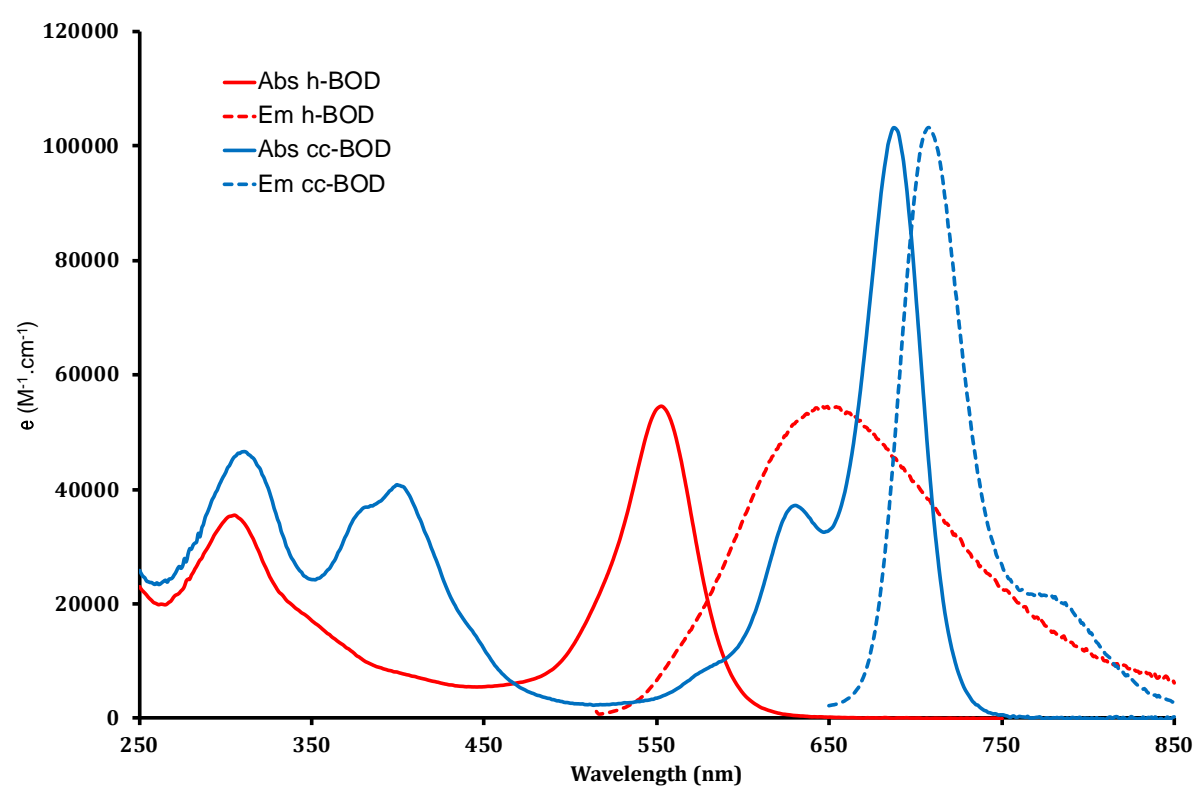


190 Figure 3 shows the absorption spectra of $\boldsymbol{h}$-BOD and $\boldsymbol{c} \boldsymbol{c}$-BOD dyes adsorbed on $\mathrm{TiO}_{2}$ film. Due to carboxylic groups of dyes that interact with $\mathrm{TiO}_{2}$, the spectra look broad. However, we clearly observed similar trends with the previous solution measurement, including a really much broader spectrum for the $\boldsymbol{c} \boldsymbol{c}$-BOD up to the NIR region as compared to the $\boldsymbol{h}$-BOD dye.

194

195

196

197

198

199

200

201

202

203

204

205

206

207

208

209

210

211

212

213

214

215

216

217

218

219

220

221

222

223

224

225

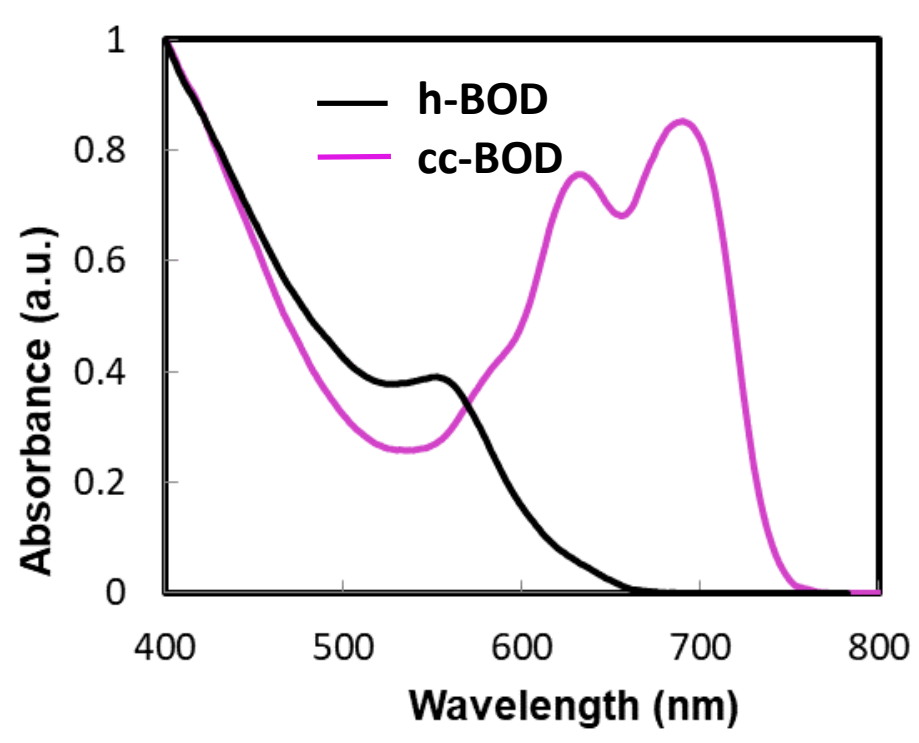

Figure 3. Absorption spectra of $\boldsymbol{h}$-BOD and $\boldsymbol{c} \boldsymbol{c}$-BOD on $\mathrm{TiO}_{2}$

To compute the electron transfer from the excited state of dye molecules to the conduction band of the respective $\mathrm{TiO}_{2}$, the ionization potential (IP), equivalent to ground state oxidation potential, of $\boldsymbol{h}$-BOD and $\boldsymbol{c} \boldsymbol{c}$-BOD anchored to $\mathrm{TiO}_{2}$ film were also measured (Figure S8 and Figure S9) using a photoemission yield spectrometer (Riken Keiki AC-3E). The findings are

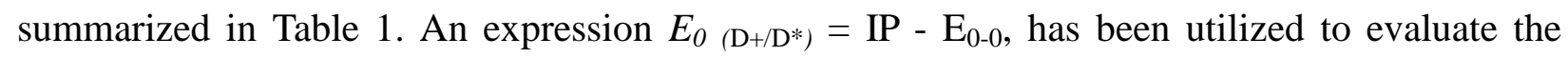
excited state oxidation potentials $\left(E_{0}\left(\mathrm{D}+/ \mathbb{D}^{*}\right)\right)$ levels of $\boldsymbol{h}$-BOD and $\boldsymbol{c} \boldsymbol{c}$-BOD which showed values of -3.81 and $-4.03 \mathrm{eV}$, respectively (Table 1). Compared with $\boldsymbol{h}$-BOD cross-conjugated BODIPY dye, $\boldsymbol{c} \boldsymbol{c}$-BOD exhibits a decrease in the $\mathrm{E}_{0-0}$ energy gap which leads to a red shift of the absorption bands with comparatively positive $E_{0\left(\mathrm{D}+/ \mathrm{D}^{*}\right)}$ levels. The $E_{0\left(\mathrm{D}+/ \mathrm{D}^{*}\right)}$ for $\boldsymbol{h}$-BOD and $\boldsymbol{c} \boldsymbol{c}$ BOD are located over the conduction band edge of the $\mathrm{TiO}_{2}{ }^{42}$. Therefore, an efficient excitedstate injection into the conduction band of $\mathrm{TiO}_{2}$ is expected for the DSSCs fabricate with $\boldsymbol{h}$-BOD and $c \boldsymbol{c}$-BOD dyes (Figure 4). Apparently, the ground state oxidation potentials (equivalent to the ionization potential, IP) were more positive than the redox potential of $\mathrm{I}^{-} / \mathrm{I}_{3}{ }^{-}$couple $(-5.2 \mathrm{eV})$, 
226 which indicates efficient dye regeneration. HOMO levels of $\boldsymbol{h}$-BOD and $\boldsymbol{c c}$-BOD were estimated, 227 by cyclic voltammetry (CV), of about $-5.49 \mathrm{eV}$ and $-5.36 \mathrm{eV}$, respectively (Figure S12 and Table 228 S1). If considering the expected down-shifting of HOMO levels when the dyes are grafted onto 229 the $\mathrm{TiO}_{2}$, these HOMO level values, obtained by $\mathrm{CV}$, are comparable with those obtained from 230 PESA measurement on $\mathrm{TiO}_{2}$ thin-films (deprotonation of the dye's carboxylic acid group to be 231 covalently bonded to the $\mathrm{TiO}_{2}$ ). The redox processes of the dyes were reproducible as shown in 232 Figure S12b,c.

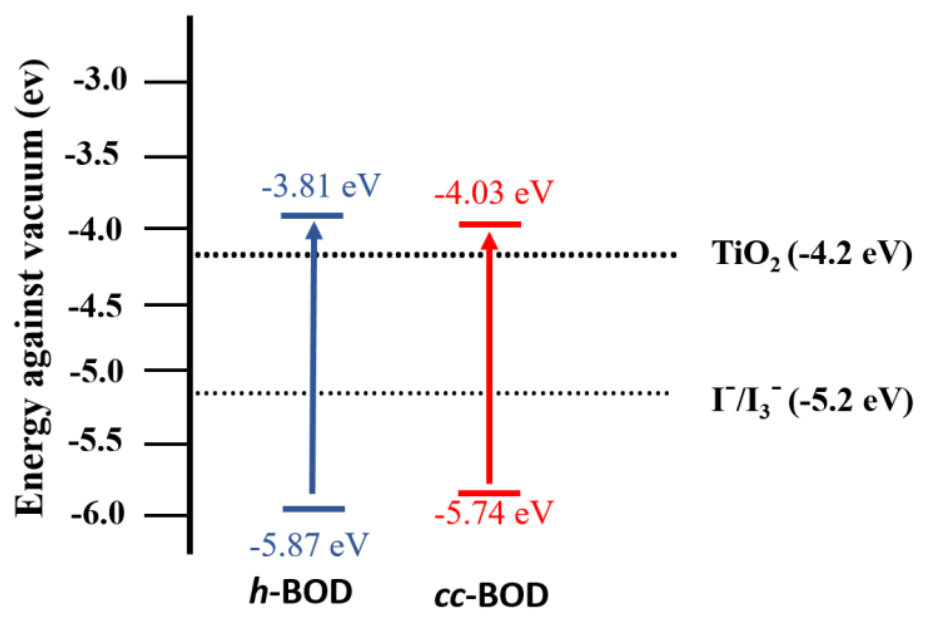

Figure 4. Energy-level diagram of $\boldsymbol{h}$-BOD and $\boldsymbol{c} \boldsymbol{c}$-BOD, electrolyte and $\mathrm{TiO}_{2}$.

Table 1. Photophysical parameters of $\boldsymbol{h}$-BOD and $\boldsymbol{c c}$-BOD Bodipy dyes.

\begin{tabular}{|l|l|l|l|l|l|l|l|}
\hline Dyes & $\begin{array}{l}\lambda_{\text {abs }} \\
(\mathbf{n m})\end{array}$ & $\begin{array}{c}\boldsymbol{\varepsilon} \\
\left(\mathbf{M}^{-\mathbf{1}} \mathbf{c m}^{-\mathbf{1}}\right)\end{array}$ & $\begin{array}{c}\lambda_{\text {abs }} \\
\mathbf{o n ~ T i O} \\
(\mathbf{n m})\end{array}$ & $\begin{array}{l}\lambda_{\text {em }} \\
(\mathbf{n m})\end{array}$ & $\begin{array}{l}\boldsymbol{E}_{\mathbf{0 - 0}} \\
(\mathbf{e V})^{\mathbf{a})}\end{array}$ & $\begin{array}{c}\boldsymbol{I P} \\
(\mathbf{e V})^{\mathbf{b})}\end{array}$ & $\begin{array}{c}\mathbf{E}_{\mathbf{0}} \mathbf{D}^{+} / \mathbf{D}^{*} \\
(\mathbf{e V})^{\mathbf{c})}\end{array}$ \\
\hline $\boldsymbol{h}$-BOD & 553 & 54500 & 560 & 652 & 2.06 & -5.87 & -3.81 \\
\hline$c c$-BOD & 688 & 102000 & 696 & 708 & 1.71 & -5.74 & -4.03 \\
\hline
\end{tabular}

a) Optical bandgap, $E_{0-0}$, was determined from UV-visible solution measurements.

244 photoemission yield spectrometer (Riken Keiki AC-3E) (see figure S8 and S9)

$24{ }^{c)}$ Excited-state oxidation potential, $E_{0\left(\mathrm{D}+/ \mathrm{D}^{*}\right)}$ was calculated from $E_{0\left(D^{+} / D^{*}\right)}=I P-E_{0-0}$. 


\subsection{Photovoltaic properties}

249 Due to the high and appealing optoelectronic properties of $\boldsymbol{c c}$-BOD and to a lesser extent of $250 \boldsymbol{h}$-BOD, DSSCs were fabricated. The elaboration procedures have been reported in section 2. 251 The photovoltaic parameters measured under AM 1.5G irradiation $\left(100 \mathrm{~mW} \mathrm{~cm} \mathrm{~cm}^{-2}\right.$ ) have been 252 summarized in Table 2 and shown in Figure 5. DSSCs sensitized with $\boldsymbol{c c}$-BOD showed high 253 photovoltaic response in the VIS-NIR region with a broad IPCE of approximately $60 \%$ in the 254 350-720 $\mathrm{nm}$ range (Figure 5a). Consequently, the $c \boldsymbol{c}$-BOD dye-based devices exhibit pretty high 255 photovoltaic performances with a PCE of $6.02 \%$ at maximum, including high photovoltaic 256 parameters, short-circuit photocurrent density $\left(J_{s c}\right)$ of $15.43 \mathrm{~mA} . \mathrm{cm}^{-2}$ and fill factors $(F F)$ of $71 \%$, 257 except the open-circuit photovoltage $\left(V_{o c}\right)$ which remains moderate (Figure 5b). Devices 258 elaborated from $\boldsymbol{h}$-BOD also showed IPCE > 60\% but however on really blue-shifted and 259 narrowest wavelength range $(350-570 \mathrm{~nm})$. Consequently, the PCE is much lower, 3.70\%, 260 mainly because of a decreased $J_{\mathrm{SC}}$ of $9.69 \mathrm{~mA} \mathrm{~cm}^{-2}$. The $V \mathrm{oc}$ and $F F$ being really close the ones 261 previously measured with $\boldsymbol{c c}$-BOD. From these photovoltaic measurements, it is rather obvious 262 that the benefit of our new cross-conjugated design in terms of optical properties is responsible 263 for the improved photovoltaic performances.

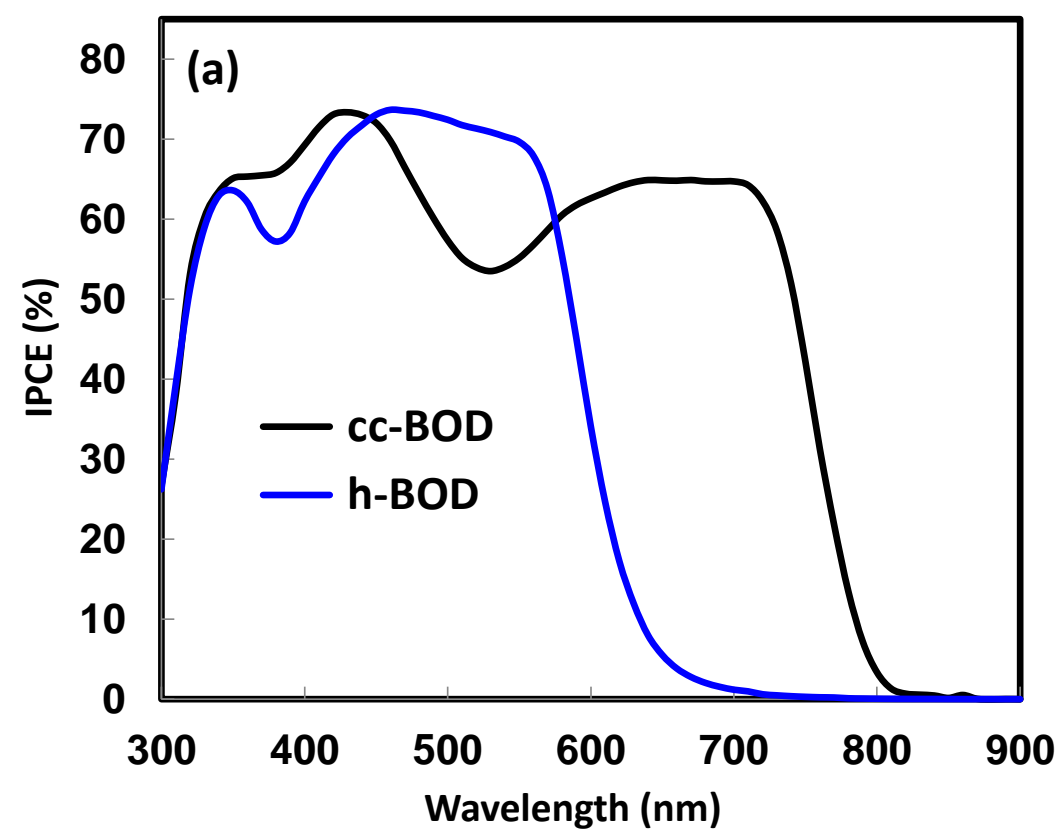




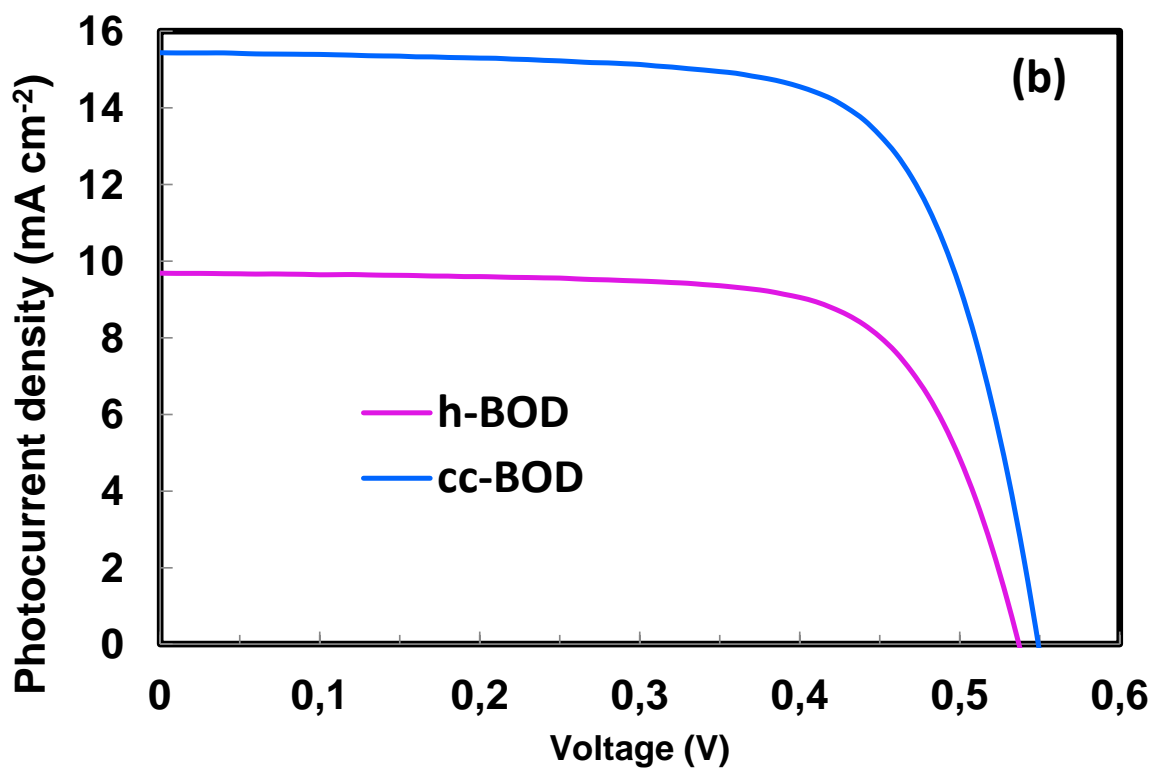

268 Figure 5. (a) IPCE spectra and (b) $J-V$ curves for DSSCs with the $\boldsymbol{h}$-BOD and $\boldsymbol{c}$-BOD Bodipy 269 dyes. Electrolyte composed of $0.6 \mathrm{M}$ dimethylpropyl-imidazolium iodide, $0.05 \mathrm{M} \mathrm{I}_{2}, 0.1 \mathrm{M}$ LiI 270 and $0.05 \mathrm{M}$ 4-tert-butylpyridine in acetonitrile.

Table 2. Photovoltaic parameters of the fabricated DSSCs

\begin{tabular}{|c|c|c|c|c|c|c|c|}
\hline \multirow{2}{*}{ Dye } & \multirow{2}{*}{$\begin{array}{c}J_{\mathrm{SC}} \\
{\left[\mathrm{mA}_{2}^{\mathrm{m}} \mathrm{cm}^{-}\right.}\end{array}$} & \multirow{2}{*}{$\begin{array}{l}V_{\mathrm{OC}} \\
{[\mathrm{V}]}\end{array}$} & \multirow{2}{*}{$F F$} & \multirow{2}{*}{$\begin{array}{c}\eta \\
{[\%]}\end{array}$} & \multicolumn{2}{|c|}{$\begin{array}{l}\text { IPCE } \\
{[\%]}\end{array}$} & \multirow{2}{*}{$\begin{array}{l}\text { Adsorbed amount } \\
\text { of dye }\left[\mathrm{mol} \mathrm{cm}{ }^{-2}\right]\end{array}$} \\
\hline & & & & & $\begin{array}{l}530 \\
\mathrm{~nm}\end{array}$ & $\begin{array}{l}700 \\
\mathrm{~nm}\end{array}$ & \\
\hline$h$-BOD & 9.69 & 0.537 & 0.711 & 3.70 & 71 & 1 & $1.23 \times 10^{-7}$ \\
\hline$c c-\mathbf{B O D}$ & 15.43 & 0.549 & 0.711 & 6.02 & 53 & 65 & $1.18 \times 10^{-7}$ \\
\hline $\begin{array}{l}h \text {-BOD + } c c-\mathrm{BOD} \\
(\text { dye ratio; } 1: 2)\end{array}$ & 16.07 & 0.561 & 0.688 & 6.20 & 69 & 63 & $\begin{array}{l}8.03 \times 10^{-8}(h \text {-BOD }) \\
7.83 \times 10^{-8}(c c-\mathrm{BOD})\end{array}$ \\
\hline
\end{tabular}



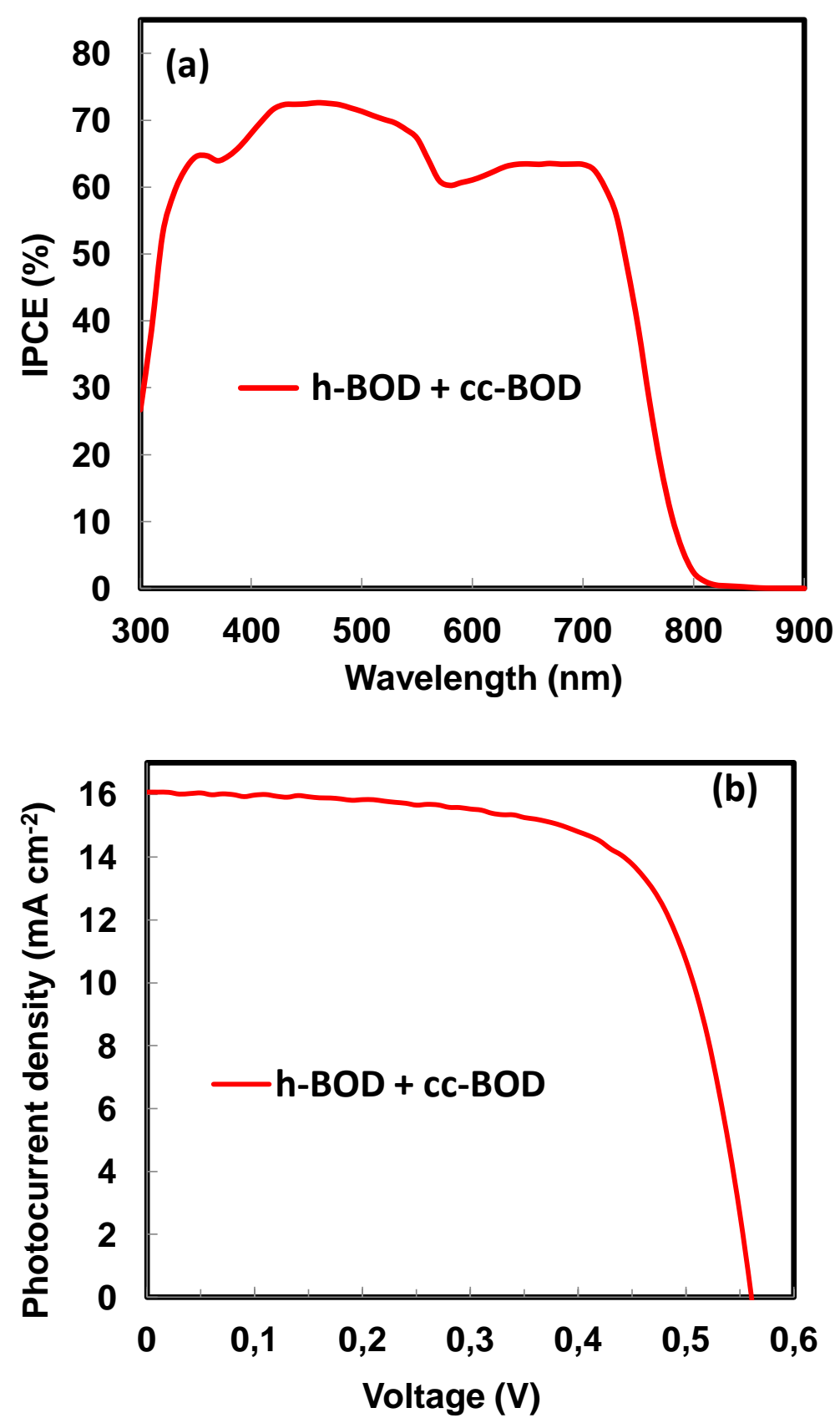

Figure 6. (a) IPCE spectra and (b) $J$ - $V$ curves for DSSCs co-sensitized with $\boldsymbol{h}$-BOD + $\boldsymbol{c} \boldsymbol{c}$-BOD. Electrolyte composed of $0.6 \mathrm{M}$ dimethylpropyl-imidazolium iodide, $0.05 \mathrm{M} \mathrm{I}_{2}, 0.1 \mathrm{M}$ LiI and $0.05 \mathrm{M}$ 4-tert-butylpyridine in acetonitrile.

284 Interestingly, from Figure 3, one can noticed that despite a partial overlap of the absorption 285 spectra of both dyes, $\boldsymbol{h}$-BOD exhibits a higher absorption feature in the 450-570 $\mathrm{nm}$ wavelength 
range. It is therefore attractive to try to incorporate both dyes into the same device, thus called co-sensitized DSSC. As anticipated, the co-sensitized DSSC based on $\boldsymbol{h}$-BOD + $\boldsymbol{c} \boldsymbol{c}$-BOD showed a high IPCE of more than $60 \%$ over the whole $330-720 \mathrm{~nm}$ region with an absorption onset up to $800 \mathrm{~nm}$ (Figure 6a). In comparison to the single $\boldsymbol{c c}$-BOD dye, the co-sensitized $\boldsymbol{h}$-BOD $+\boldsymbol{c c}$ BOD system shows substantially increased IPCE in the visible region without decreasing IPCE in the NIR region. The IPCE at $530 \mathrm{~nm}$ increased from $53 \%$ for single $c c$-BOD dye to $69 \%$ for $\boldsymbol{h}$-BOD $+\boldsymbol{c} \boldsymbol{c}$-BOD. Even though the adsorbed amount of $\boldsymbol{c} \boldsymbol{c}$-BOD in the $\boldsymbol{c} \boldsymbol{c}$-BOD alone cell decrease from $1.18 \times 10^{-7} \mathrm{~mol} \mathrm{~cm}^{-2}$ to $7.83 \times 10^{-8} \mathrm{~mol} \mathrm{~cm}^{-2}$ in the $\boldsymbol{h}$-BOD $+\boldsymbol{c} \boldsymbol{c}$-BOD cell (Table 2), the IPCE spectrum of $c c$-BOD at $700 \mathrm{~nm}$ decreases only from $65 \%$ to $63 \%$ for co-sensitized $\boldsymbol{h}$-BOD + $\boldsymbol{c} \boldsymbol{c}$-BOD, where mainly $\boldsymbol{c c}$-BOD shows a photo-response. These results suggest that $\boldsymbol{h}$ BOD does not affect the light harvesting efficiency of $c c$-BOD on $\mathrm{TiO}_{2}$ film in the co-sensitized $\boldsymbol{h}$-BOD + $\boldsymbol{c} \boldsymbol{c}$-BOD system. Consequently, an even improved photovoltaic performance in regard to previous elaborated DSSCs, inducing an enhanced $J_{\mathrm{SC}}$ of $16.07 \mathrm{~mA} \mathrm{~cm}^{-2}$, was measured for the co-sensitized DSSC. The $V_{\mathrm{OC}}$ and FF remain quite unmodified (see Table 2, Figure 6b) and resulted in a PCE of $6.20 \%$.

\subsection{CEM and IMVS measurements}

303 For determining the dynamics of charge recombination, the electron lifetime $(\tau)$ in the DSSCs is 304 a key parameter to determine the which is related to the device $\mathrm{V}_{\mathrm{oc}}$. As the $\mathrm{V}_{\mathrm{oc}}$ of a DSSC 305 depends on the charge recombination reactions rather than molecular structures of the dyes, it is 306 important to explore the role of the fabricated sensitizer based DSSCs in this aspect. ${ }^{36}$ The 307 relative conduction band positions and electron lifetimes in the DSSCs fabricated with either $\boldsymbol{h}$ 308 BOD, $\boldsymbol{c} \boldsymbol{c}$-BOD single dyes and $\boldsymbol{h}$-BOD + $\boldsymbol{c} \boldsymbol{c}$-BOD co-sensitized dyes were examined to 309 comprehend the difference of the measured $V_{\mathrm{oc}}$ for the DSSCs. Initially, the relative conduction 310 band position of $\mathrm{TiO}_{2}$ was measured by charge extraction method (CEM). Figure 7a shows that 311 DSSCs sensitized with $\boldsymbol{h}$-BOD, $\boldsymbol{c} \boldsymbol{c}$-BOD single dyes and $\boldsymbol{h}$-BOD $\boldsymbol{c} \boldsymbol{c}$-BOD co-sensitized dye 312 display a similar linear increase in electron density as a function of $\mathrm{V}_{\text {oc }}$. This indicates that $\boldsymbol{h}$ 313 BOD, $\boldsymbol{c} \boldsymbol{c}$-BOD single dyes and $\boldsymbol{h}$-BOD + $\boldsymbol{c} \boldsymbol{c}$-BOD co-sensitized dye cells have the same 314 conduction band edge of $\mathrm{TiO}_{2}$ irrespective to the molecular structures and co-sensitization. We 315 have further investigated the electron lifetime $(\tau$, which reflects the degree of electron 316 recombination) of the DSSCs sensitized with $\boldsymbol{h}$-BOD, $\boldsymbol{c} \boldsymbol{c}$-BOD single dyes and $\boldsymbol{h}$-BOD $+\boldsymbol{c c}$ - 
317 BOD dyes by means of intensity-modulated photovoltage spectroscopy to understand the 318 differences between the $\mathrm{V}_{\mathrm{oc}}$ values of the respective DSSCs which is shown in Figure 7 (b). It is 319 clear that at a fixed $\mathrm{V}_{\mathrm{OC}}$, the lifetime decreases as $\boldsymbol{h}$-BOD $+\boldsymbol{c} \boldsymbol{c}$-BOD $>\boldsymbol{c} \boldsymbol{c}$-BOD $>\boldsymbol{h}$-BOD, which 320 is in accord with the order of decreasing $\mathrm{V}_{\mathrm{OC}}$ observed in the respective DSSCs. The longer 321 lifetime observed for the $\boldsymbol{h}$-BOD + $\boldsymbol{c} \boldsymbol{c}$-BOD based DSSC compared to cc-BOD and $\boldsymbol{h}$-BOD 322 based DSSCs suggests that the co-sensitized DSSC significantly suppressed the recombination of 323 electrons in the $\mathrm{TiO}_{2}$ film with $\mathrm{I}_{3}{ }^{-}$.

324

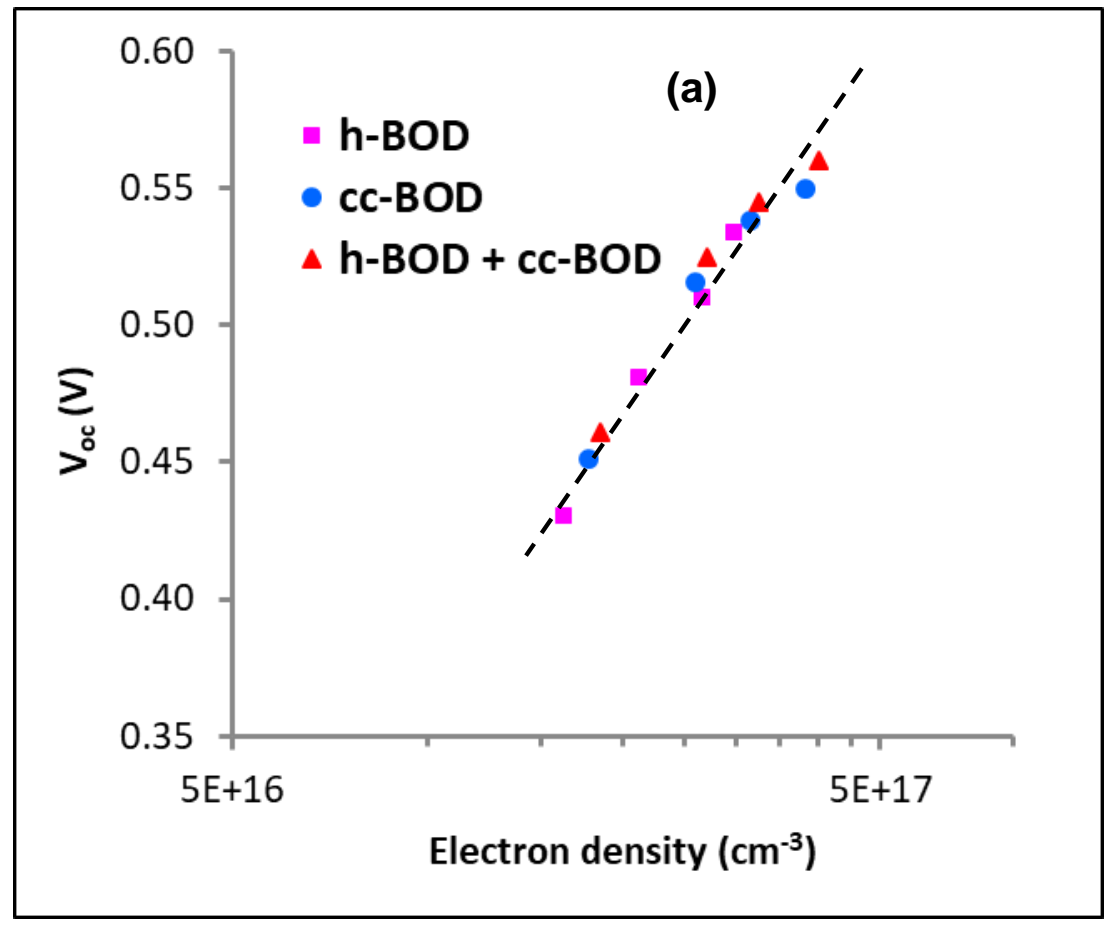




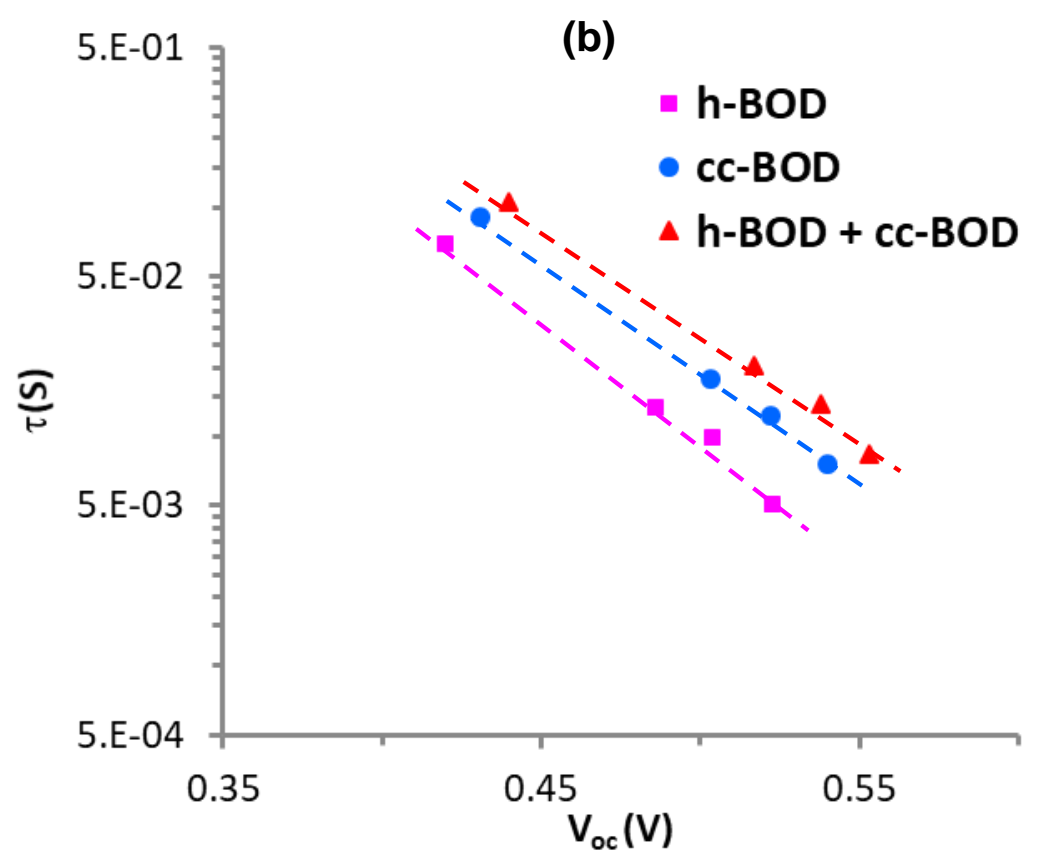

Figure 7. a) Electron density, and b) electron lifetime $(\tau)$ as a function of open-circuit photovoltage for DSSCs sensitized with $\boldsymbol{h}$-BOD, $\boldsymbol{c} \boldsymbol{c}$-BOD single dye and $\boldsymbol{h}$-BOD $+\boldsymbol{c} \boldsymbol{c}$-BOD dyes.

\section{Conclusion}

By combining the horizontal and vertical designs in one single dye, called cross-conjugated design, we designed and synthesized a new BODIPY-based dye, called cross-conjugated BODIPY, $c c$-BOD. It exhibits a strong a UV-visible-NIR absorption. Compared to a more standard BODIPY dye, using similar functional groups and based on a horizontal design, called $\boldsymbol{h}$-BOD, the new $\boldsymbol{c c}$-BOD exhibits clearly the highest conjugation and the highest light harvesting properties. Applied as photosensitizers in DSSCs, the $\boldsymbol{c} c$-BOD dye has led to significantly higher photovoltaic performances than the $\boldsymbol{h}$-BOD, with maximum PCE measured at $6.02 \%$ instead of $3.7 \%$. However, the simultaneous use of both dyes $\boldsymbol{h}$-BOD $+\boldsymbol{c} \boldsymbol{c}$-BOD as cosensitizer in DSSCs, led to a further PCE increase up to 6.2\%, due to their complementary absorption properties. These results highlight the beneficial impact of our novel cross-conjugated BODIPY-based design in developing NIR dyes for the fabrication of high efficiency DSSCs.

\section{Acknowledgements}

This work was supported by the Deanship of Scientific Research (DSR), University of Jeddah, Jeddah, under grant No. (UJ-12-18-ICP). The authors, therefore, acknowledge with thanks DSR 
technical and financial support. J.-J. L., T.H.C and A.I. acknowledges the support of NRF350 2016M1A2A2940912 and 2015M1A2A2054996. A. I. also acknowledges the support from JSPS 351 KAKENHI grant no. 18H02079.

\section{Appendix A. Supporting information}

354 Supplementary data associated with this article can be found in the online version at doi:000.

355

356

\section{7}

358

359

360

361

362

363

364

365

366

367

368

369

370

371

372

373

374

375

376

377

378

379 380

\section{References:}

1. B. O'regan and M. Grätzel, nature, 1991, 353, 737.

2. M. Grätzel, Journal of Photochemistry and Photobiology A: Chemistry, 2004, 164, 3-14.

3. M. Grätzel, Inorganic chemistry, 2005, 44, 6841-6851.

4. A. Hagfeldt, G. Boschloo, L. Sun, L. Kloo and H. Pettersson, Chemical reviews, 2010, 110, 6595-6663.

5. W. A. El-Said, M. Abdel-Shakour and A. M. Abd-Elnaiem, Materials Letters, 2018, 222, 126-130.

6. Ö. Birel, S. Nadeem and H. Duman, Journal of fluorescence, 2017, 27, 1075-1085.

7. J. Gong, K. Sumathy, Q. Qiao and Z. Zhou, Renewable and Sustainable Energy Reviews, 2017, 68, 234-246.

8. Y. Chiba, A. Islam, Y. Watanabe, R. Komiya, N. Koide and L. Han, Japanese journal of applied physics, 2006, 45, L638.

9. H. Tian, X. Yang, R. Chen, A. Hagfeldt and L. Sun, Energy \& Environmental Science, 2009, 2, 674-677.

10. L. Han, A. Islam, H. Chen, C. Malapaka, B. Chiranjeevi, S. Zhang, X. Yang and M. Yanagida, Energy \& Environmental Science, 2012, 5, 6057-6060.

11. G. Lingamallu, V. S. K. Jonnadula, K. Devulapally, T. H. Chowdhury, S. P. Singh, I. Bedja and A. Islam, Journal of Materials Chemistry C, 2019.

12. J.-H. Yum, E. Baranoff, S. Wenger, M. K. Nazeeruddin and M. Grätzel, Energy \& Environmental Science, 2011, 4, 842-857.

13. N. Duvva, G. Reddy, S. P. Singh, T. H. Chowdhury, I. Bedja, A. Islam and L. Giribabu, New Journal of Chemistry, 2019. 
381 14. M. Abdel-Shakour, W. A. El-Said, I. M. Abdellah, R. Su and A. El-Shafei, Journal of 382 Materials Science: Materials in Electronics, 2019, 30, 5081-5091.

383 15. A. Mishra, M. K. Fischer and P. Bäuerle, Angewandte Chemie International Edition, $384 \quad 2009,48,2474-2499$.

385 16. Y. Ooyama and Y. Harima, European Journal of Organic Chemistry, 2009, 2009, 29033862934.

387 17. C. Qin, Y. Numata, S. Zhang, X. Yang, A. Islam, K. Zhang, H. Chen and L. Han, $388 \quad$ Advanced Functional Materials, 2014, 24, 3059-3066.

389 18. M. M. Jadhav, T. H. Chowdhury, I. Bedja, D. Patil, A. Islam and N. Sekar, Dyes and 390

20. D. Patil, M. Jadhav, K. Avhad, T. H. Chowdhury, A. Islam, I. Bedja and N. Sekar, New Journal of Chemistry, 2018, 42, 11555-11564.

21. K. Avhad, M. Jadhav, D. Patil, T. H. Chowdhury, A. Islam, I. Bedja and N. Sekar, Organic Electronics, 2019, 65, 386-393.

22. Q. Huaulmé, A. Sutter, S. Fall, D. Jacquemin, P. Lévêque, P. Retailleau, G. Ulrich and N. Leclerc, Journal of Materials Chemistry C, 2018, 6, 9925-9931.

23. A. Zampetti, A. Minotto, B. M. Squeo, V. G. Gregoriou, S. Allard, U. Scherf, C. L.

24. T. Kowada, H. Maeda and K. Kikuchi, Chemical Society Reviews, 2015, 44, 4953-4972.

25. L. Huang, Z. Li, Y. Zhao, Y. Zhang, S. Wu, J. Zhao and G. Han, Journal of the American Chemical Society, 2016, 138, 14586-14591.

28. H. Klfout, A. Stewart, M. Elkhalifa and H. He, ACS applied materials \& interfaces, 2017, 9, 39873-39889.

26. I. Bulut, Q. Huaulmé, A. Mirloup, P. Chávez, S. Fall, A. Hébraud, S. Méry, B. Heinrich, T. Heiser and P. Lévêque, ChemSusChem, 2017, 10, 1878-1882.

27. S. P. Singh and T. Gayathri, European Journal of Organic Chemistry, 2014, 2014, 46894707.

29. S. Kolemen, O. A. Bozdemir, Y. Cakmak, G. Barin, S. Erten-Ela, M. Marszalek, J.-H. Yum, S. M. Zakeeruddin, M. K. Nazeeruddin and M. Grätzel, Chemical Science, 2011, 2, 
949-954.

413 30. Y. Ooyama, Y. Hagiwara, T. Mizumo, Y. Harima and J. Ohshita, New Journal of $414 \quad$ Chemistry, 2013, 37, 2479-2485.

415 31. J.-F. Lefebvre, X.-Z. Sun, J. A. Calladine, M. W. George and E. A. Gibson, Chemical $416 \quad$ Communications, 2014, 50, 5258-5260.

417 32. D. Kumaresan, R. P. Thummel, T. Bura, G. Ulrich and R. Ziessel, Chemistry-A European $418 \quad$ Journal, 2009, 15, 6335-6339.

419 33. Q. Huaulmé, C. Aumaitre, O. V. Kontkanen, D. Beljonne, A. Sutter, G. Ulrich, R. 420 Demadrille and N. Leclerc, Beilstein Journal of Organic Chemistry, 2019, 15, 1758-1768.

421 34. T. Bura, P. Retailleau and R. Ziessel, Angewandte Chemie International Edition, 2010, 49, $422 \quad 6659-6663$.

423 35. C. Qin, A. Mirloup, N. Leclerc, A. Islam, A. El- Shafei, L. Han and R. Ziessel, Advanced $424 \quad$ Energy Materials, 2014, 4, 1400085.

425 36. A. Islam, T. H. Chowdhury, C. Qin, L. Han, J.-J. Lee, I. M. Bedja, M. Akhtaruzzaman, K. 426 Sopian, A. Mirloup and N. Leclerc, Sustainable Energy \& Fuels, 2018, 2, 209-214.

427 37. G. Ulrich, C. Goze, M. Guardigli, A. Roda and R. Ziessel, Angewandte Chemie 428 International Edition, 2005, 44, 3694-3698.

429 38. A. Yella, H.-W. Lee, H. N. Tsao, C. Yi, A. K. Chandiran, M. K. Nazeeruddin, E. W.-G. 430 Diau, C.-Y. Yeh, S. M. Zakeeruddin and M. Grätzel, science, 2011, 334, 629-634.

431 39. T. Bura, N. Leclerc, S. Fall, P. Lévêque, T. Heiser, P. Retailleau, S. Rihn, A. Mirloup and 432 R. Ziessel, Journal of the American Chemical Society, 2012, 134, 17404-17407.

433 40. M. Mao, J.-B. Wang, Z.-F. Xiao, S.-Y. Dai and Q.-H. Song, Dyes and Pigments, 2012, 94, 434 224-232.

435 41. A. Bessette and G. S. Hanan, Chemical Society Reviews, 2014, 43, 3342-3405.

436 42. A. Hagfeldt and M. Graetzel, Chemical Reviews, 1995, 95, 49-68. 